\title{
Evaluasi Simpang Empat Bersinyal Jalan Kolonel Polisi M Taher Kota Jambi
}

\author{
Ahmad Safri*, Amsori M Das, Wari Dony \\ Program Studi Teknik Sipil Universitas Batanghari Jambi \\ *Correspondence email: ahmadsafri1300822201009@gmail.com
}

\begin{abstract}
Abstrak. Kinerja simpang empat bersinyal berdasarkan Metode MKJI 1997 dilakukan dengan menghitung tingkat pelayan ( LOS ), derajat kejenuhan, tundaan rata-rata,panjang antrian dan kapasitas pada titik lokasi penelitian sehingga dapat mengetahui tingkat pelayanan dan kepadatan. Lokasi yang menjadi tempat penelitian yakni simpang Persijam yang memiliki empat lengan yakni Jalan Kol.Pol.M.Taher arah Jalan Soekarno Hatta, Jalan H.M.Yusuf Nasri, Jalan Kol.Pol.M.Taher dari arah jalan Gr.Djamin Datuk Bagindo, Jalan Teuku Sulaiman.Data yang digunakan merupakan data sekunder dan data primer. Dari hasil penelitian pada simpang bersinyal di persimpangan persijam,Jambi dengan menggunakan metode MKJI 1997 diperoleh tingkat pelayanan D dengan nilai derajat kejenuhan mencapai Jln. Kol.Pol M Taher dari arah Jln.Soekarno Hatta DS 0,86 Jln. H M Yusuf Nasri DS 0,82. Jln. Kol.Pol M Taher arah Jln.Gr.Djamin Datuk Bagindo DS 0,86 Jln. Tengku Sulaiman DS 0,82.
\end{abstract}

Kata Kunci: Simpang Bersinyal; Kinerja; Survei; LOS

\section{PENDAHULUAN}

Perubahan pertumbuhan kepadatan penduduk yang begitu cepat tentunya dapat berpengaruh pada permasalahan yang semakin kompleks, khususnya pada peningkatan arus lalu lintas yang tidak seimbang dengan ketersediaan kapasitas jalan yang ada. Transportasi merupakan salah satu aspek kehidupan yang mempunyai peranan penting dalam menunjang kegiatan untuk memenuhi kebutuhan manusia, dengan adanya perkembangan sarana dan prasarana transportasi maka akan semakin memudahkan manusia dalam melakukan perpindahan tempat untuk mencapai tujuan.

Ruas jalan pada simpang terdiri dari (4) empat ruas yakni Jalan Kol.Pol.M.Taher Jalan H.M.Yusuf Nasri Jalan Kol.Pol.M.Taher Jalan Tengku Sulaiman.

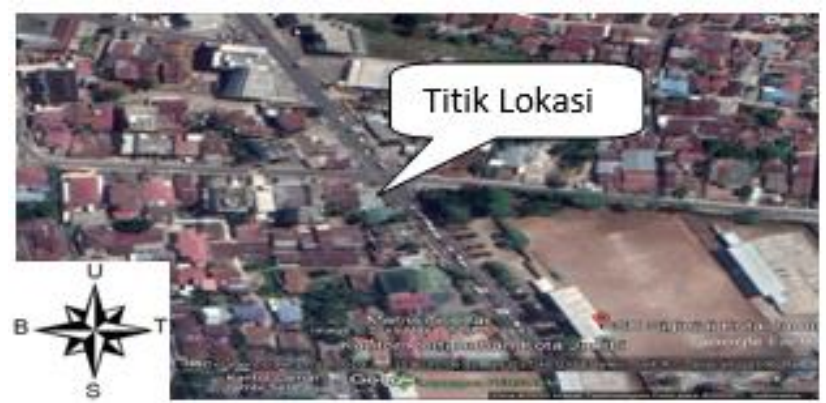

Gambar 1. simpang empat Persijam

\section{METODE}

Metode yang dilakukan dalam kajian evaluasi kinerja pelayanan ini adalah metode MKJI 1997 dengan melakukan observasi lapangan. Hal yang dilakukan terkait dengan observasi lapangan diatas perlu dilakukan untuk mengetahui kinerja pelayanan simpang masuk dalam kondisi LOS apa. Selain itu perlu diketahuinya jenis kendaran yang melewati simpang empat Persijam, sehingga dapat kita ketahui tingkat peayanan simpang.

Tabel 1. Standar Nilai LOS

\begin{tabular}{ccl}
\hline Tingkat Pelayanan & Rasio ( V/C ) & \multicolumn{1}{c}{ Karateristik } \\
\hline A & $<0,60$ & $\begin{array}{l}\text { Arus bebas volume rendah dan kecepatan tinggi, pengemudi dapat memilih } \\
\text { kecepatan yang dikehendaki }\end{array}$ \\
B & $0,60<\mathrm{V} / \mathrm{C}<0,70$ & $\begin{array}{l}\text { Arus bebas, volume rendah dan kecepatan tinggi, pengemudi dapat memilih } \\
\text { kecepatan yang dikehendaki }\end{array}$ \\
$\mathrm{C}$ & $0,70<\mathrm{V} / \mathrm{C}<0,80$ & Arus stabil arus dapat dikontrol oleh lalu lintas \\
\hline
\end{tabular}


Tabel 2. Standar Nilai LOS ( Lanjutan )

\begin{tabular}{ccl}
\hline Tingkat Pelayanan & Rasio $(\mathrm{V} / \mathrm{C})$ & \multicolumn{1}{c}{ Karateristik } \\
\hline $\mathrm{D}$ & $0,80<\mathrm{V} / \mathrm{C}<0,90$ & $\begin{array}{l}\text { Arus mulai tidak setabil, karena kemacetan rendah dan berbeda-beda volume } \\
\text { mendekati kapasitas }\end{array}$ \\
$\mathrm{E}$ & $0,90<\mathrm{V} / \mathrm{C}<1$ & $\begin{array}{l}\text { Arus tidak stabil kemacetan rendah dan berbeda- beda volume mendekati } \\
\text { kapasitas } \\
\text { Arus yang terhambat kemacetan rendah volume di atas kapasitas sering terjadi } \\
\text { kemacetan pada waktu yang cukup lama }\end{array}$ \\
\hline F & $>1$ &
\end{tabular}

Sumber. MKJI 1997

\section{HASIL DAN PEMBAHASAN}

Dari semua metode yang telah dilakukan didapat hasil analisis berdasarkan data yang diperoleh melalu data sekunder dan data perimer.

Tabel 3. Hasil Analisis Jln. Kolonel Polisi M Taher

\begin{tabular}{|c|c|c|c|c|c|c|c|c|c|c|c|c|c|c|c|c|}
\hline \multirow[b]{2}{*}{ No } & \multirow[b]{2}{*}{ Nama Ruas } & \multirow[b]{2}{*}{$\begin{array}{l}\text { Arus Lalu } \\
\text { Intas } \\
\mathrm{smp} / \mathrm{jam} \\
\mathrm{Q}\end{array}$} & \multirow[b]{2}{*}{$\begin{array}{c}\text { Kapasitas } \\
\text { smp/jam } \\
\text { C }\end{array}$} & \multirow[b]{2}{*}{$\begin{array}{c}\text { Derajat } \\
\text { kejenuhan } \\
\text { DS }\end{array}$} & \multicolumn{5}{|c|}{ Jumlah kendaran antri ( $\mathrm{smp}$ ) } & \multirow[b]{2}{*}{$\begin{array}{l}\text { Panjang } \\
\text { Antrian }\end{array}$} & \multirow[b]{2}{*}{$\begin{array}{c}\text { Rasio } \\
\text { Kendaraan } \\
\text { stop/smp } \\
\text { NS }\end{array}$} & \multirow[b]{2}{*}{$\begin{array}{c}\text { Jumlah } \\
\text { kendaraan } \\
\text { terhenti } \\
\text { smp/jam N sv }\end{array}$} & \multicolumn{4}{|c|}{ Tundaan } \\
\hline & & & & & $\begin{array}{l}\text { Rasio } \\
\text { Hijau }\end{array}$ & N1 & $\mathrm{N} 2$ & $\begin{array}{c}\text { Total NQ1 } \\
+ \text { NQ2 }= \\
\text { NQ }\end{array}$ & $\begin{array}{l}\text { NQ } \\
\text { Max }\end{array}$ & & & & $\begin{array}{c}\text { Tundaan lalu } \\
\text { lintas rata- } \\
\text { rata det/smp } \\
\text { DT } \\
\end{array}$ & $\begin{array}{c}\text { Tundaan } \\
\text { Geometrik } \\
\text { det } / \text { smp } \\
\text { DG }\end{array}$ & $\begin{array}{c}\text { Tundaan } \\
\text { Rata-rata } \\
\mathrm{D}=\mathrm{DT}+ \\
\text { DG }\end{array}$ & $\begin{array}{c}\text { Tundaan } \\
\text { Total D } \\
\mathrm{xQ} \\
\end{array}$ \\
\hline 1. & $\begin{array}{c}\text { Kolonel Polisi } \\
\text { M Taher }\end{array}$ & 1092 & 1263 & 0.86 & 0.21 & 0.72 & 22.87 & 23.59 & 24 & 40 & 0.91 & 925 & 34 & 4 & 38 & 47994 \\
\hline 2. & $\begin{array}{l}\text { H.M.Yusuf } \\
\text { Nasri }\end{array}$ & 297 & 274 & 0.86 & 0.17 & 0.72 & 6.21 & 6.93 & 7 & 17.5 & 1.02 & 296 & 18 & 4 & 22 & 6028 \\
\hline 3. & $\begin{array}{l}\text { Kolonel Polisi } \\
\text { M Taher }\end{array}$ & 1207 & 1473 & 0.82 & 0.25 & 0.64 & 24.58 & 25.22 & 25 & 41.6 & 0.96 & 1072 & 31 & 4 & 35 & 42245 \\
\hline 4. & $\begin{array}{l}\text { Tengku } \\
\text { Sulaiman } \\
\end{array}$ & 212 & 257 & 0.82 & 0.17 & 0.64 & 3.96 & 4.6 & 5 & 12.5 & 1.12 & 197 & 42 & 3 & 47 & 9964 \\
\hline
\end{tabular}

Sumber. Hasil Perhitungan 2020

\section{Pembahasan}

Ruas jalan meliputi panjang, jumlah lajur, kecepatan, jenis gangguan pada persimpangan, kapasitas, dan hubungan antara kecepatan dan arus pada ruas jalan tersebut. Setiap bagian harus dilengkapi dengan beberapa atribut untuk menggambarkan perilaku, karakteristik, dan kemampuan jalan tersebut. Beberapa atribut ini adalah panjang bagian, kecepatan bagian (laju aliran bebas dan kecepatan sesaat) dan kapasitas bagian, yang dinyatakan dalam unit mobil penumpang (smp) per jam.

Hasil survei lapangan yang dilakukan dengan interval waktu 15 menit di dapatkan volume arus lalu lintas. Hasil survei harus dijumlahkan terlebih dahulu untuk masing - masing jenis kendaraan dan masing - masing arah pergerakan, sehingga diperoleh nilai total arus lalu lintas. Nilai total yang didapat dalam satuan kendaraan, maka harus dikalikan terlebih dahulu dengan nilai ekivalen mobil penumpang (emp) untuk kondisi terlindung maupun terlawan agar menjadi satuan mobil penumpang (smp/jam).

Berdasarkan survei arus lalu lintas yang dilakukan pada hari senin, selasa dan sabtu dapat diketahui jam sibuk pada Jln Kolonel Polisi M Taher yaitu pada hari Sabtu 20 Juni 2020 pukul 19.00-21.00 WIB, pada JlnH.M Yusuf Nasri yaitu pada hari Sabtu 20 Juni 2020 pukul 19.00-21.00 WIB, pada Jln Kolonel Polisi M Taher arah Jln Gr Djamin Datuk Bagindo yaitu pada hari Sabtu 20 Juni 2020 pukul 19.00-21.00 WIB, dan pada Jln Tengku Sulaiman terjadi pada hari Sabtu 20 Juni 2020 pukul 16.00-18.00 WIB.

Tabel 4. Nilai EMP masing-masing kendaran untuk persimpangan bersinyal

Sumber. MKJI 1997

\begin{tabular}{cc}
\hline Penduduk Kota (Juta Jiwa) & Faktor Penyesuaian Ukuran Kota (Fcs) \\
\hline$>3,0$ & 1.05 \\
$1,0-3,0$ & 1 \\
$0,5-1,0$ & 0.94 \\
$0,1-0,5$ & 0.83 \\
$<1$ & 0.82 \\
\hline
\end{tabular}


Tabel 5. Arus Lalu Lintas

\begin{tabular}{|c|c|c|c|c|c|c|c|c|c|c|c|}
\hline \multirow{2}{*}{ Jalan } & \multirow{2}{*}{ Arah } & \multicolumn{2}{|c|}{$\begin{array}{c}\text { Kend. Ringan (LV) } \\
\text { emp terlindung }=1,0 \\
\text { emp terlawan }=1,0\end{array}$} & \multicolumn{2}{|c|}{$\begin{array}{l}\text { Kend. Berat (HV) } \\
\text { emp terlindung }=1,3 \\
\text { emp terlawan }=1,3\end{array}$} & \multicolumn{2}{|c|}{$\begin{array}{l}\text { Sepeda Motor (MC) } \\
\text { emp terlindung }=0,2 \\
\text { emp terlawan }=0,4\end{array}$} & \multicolumn{2}{|c|}{$\begin{array}{c}\text { Kend. Bermotor (MV) } \\
\text { Total }\end{array}$} & \multicolumn{2}{|c|}{$\begin{array}{c}\text { Rasio } \\
\text { Berbelok }\end{array}$} \\
\hline & & $\mathrm{Kend} / \mathrm{jam}$ & $\begin{array}{l}\text { Terlindung } \\
\text { (smp/jam) }\end{array}$ & Kend/jam & $\begin{array}{l}\text { Terlindung } \\
\text { (smp/jam) }\end{array}$ & $\mathrm{Kend} / \mathrm{jam}$ & $\begin{array}{l}\text { Terlindung } \\
\text { (smp/jam) }\end{array}$ & $\mathrm{Kend} / \mathrm{jam}$ & $\begin{array}{l}\text { Terlindung } \\
\text { (smp/jam) }\end{array}$ & PLT & PRT \\
\hline & LT & 25 & 25 & 2 & 3 & 236 & 47 & 263 & 75 & & \\
\hline Jln. Kolonel & ST & 680 & 680 & 81 & 105 & 1995 & 399 & 2756 & 912 & & \\
\hline Polisi M & RT & 76 & 76 & 3 & 4 & 125 & 25 & 204 & 105 & & \\
\hline \multirow[t]{3}{*}{ Taher } & Total & 786 & 786 & 86 & 112 & 2356 & 471 & 3,223 & 1092 & & \\
\hline & LT & 15 & 15 & 2 & 3 & 161 & 32 & 178 & 35 & & \\
\hline & ST & 65 & 65 & 1 & 1 & 182 & 36 & 248 & 83 & & \\
\hline Jln.H.M & RT & 75 & 75 & 1 & 1 & 345 & 69 & 421 & 108 & & \\
\hline \multirow[t]{2}{*}{ Yusuf Nasri } & Total & 155 & 155 & 4 & 5 & 688 & 137 & 847 & 297 & & \\
\hline & LT & 60 & 60 & 2 & 3 & 483 & 97 & 545 & 90 & & \\
\hline Jln.Kolonel & ST & 796 & 796 & 8 & 10 & 1731 & 346 & 2535 & 1019 & & \\
\hline Polisi M & RT & 130 & 130 & 10 & 13 & 263 & 53 & 403 & 98 & & \\
\hline \multirow[t]{3}{*}{ Taher } & Total & 986 & 986 & 20 & 36 & 2477 & 496 & 3483 & 1207 & & \\
\hline & LT & 40 & 40 & 1 & 1 & 60 & 12 & 101 & 43 & & \\
\hline & ST & 75 & 75 & 2 & 3 & 360 & 72 & 436 & 118 & & \\
\hline Jln.Tengku & RT & 35 & 35 & 1 & 1 & 125 & 25 & 161 & 58 & & \\
\hline Sulaiman & Total & 150 & 150 & 4 & 5 & 545 & 109 & 698 & 212 & & \\
\hline
\end{tabular}

Sumber. Hasil perhitungan 2020

Keterangan :

LT : Left Trun ( Belok Kiri ) ST : Straight ( Lurus ) RT : Right Trun (Belok Kanan )

\section{Nilai Kapasitas}

Menghitung Nilai kapasitas dengan persamaan :

$\mathrm{C}=\mathrm{S} \times \frac{g}{g}$

Dimana ${ }^{6}$

$\mathrm{S}:$ Arus jenuh (smp/jam)

$\mathrm{g}:$ Waktu Hijau (det)

c : Waktu Siklus (det)

1) Jln Kolonel Polisi M Taher C $=5895$ x $18 / 84$

$\mathrm{C}=1263 \mathrm{smp} / \mathrm{jam}$

2) Jln H.M Yusuf Nasri $\mathrm{C}=1536 \times 15 / 84$

$\mathrm{C}=274 \mathrm{smp} / \mathrm{jam}$

3) Jln. Kolonel Polisis M Taher C $=5892 \times 21 / 84$

$\mathrm{C}=1473 \mathrm{smp} / \mathrm{jam}$

4) Jln. Tengku Sulaiman $C=1440 \times 15 / 84$

$\mathrm{C}=257 \mathrm{smp} / \mathrm{jam}$

Nilai Derajat Kejenuhan

1) Jln Kolonel Polisi M Taher DS $=Q / C$

$\mathrm{DS}=1092 / 1263$

$\mathrm{DS}=0,86$

2) Jln H.M Yusuf Nasri DS $=Q / C$

$\mathrm{DS}=238 / 274$

$\mathrm{DS}=0,86$

3) Jln. Kolonel Polisi M Taher DS $=\mathrm{Q} / \mathrm{C}$

$\mathrm{DS}=1207 / 1473$

$\mathrm{DS}=0,82$

4) Jln Tengku Sulaiman DS $=Q / C$

DS $=212 / 257$

$\mathrm{DS}=0,82$

\section{Panjang Antrian}

Panjang antrian merupakan banyaknya kendaraan yang berada pada simpang tiap jalur saat nyala lampu merah. 
1) Jln Kolonel Polisi $M$ Taher $\mathrm{NQ}_{1}=0,72$

$\mathrm{NQ}_{2}=22,87$

$\mathrm{NQ}=0,72+22,87=23,59 \mathrm{QL}=\frac{24 \times 20}{12}=40 \mathrm{~m}$

2) Jln H.M Yusuf Nasri $\mathrm{NQ}_{1}=0,72$

$\mathrm{NQ}_{2}=6,21$

$\mathrm{NQ}=0,72+6,21=6,93 \mathrm{QL}=\frac{7 \times 20}{s}=17,5 \mathrm{~m}$

3) Jln Kolonel Polisi $M$ Taher $\mathrm{NQ}_{1}=0,64$

$\mathrm{NQ}_{2}=24,58$

$\mathrm{NQ}=0,64+24,58=25,22 \mathrm{QL}=\frac{25 \times 20}{12}=41,6 \mathrm{~m}$

4) Jln Tengku Sulaiman $N_{1}=0,64$

$\mathrm{NQ}_{2}=3,96$

$\mathrm{NQ}=0,64+3,96=4,6 \mathrm{QL}=\frac{5 \times 20}{s}=12,5 \mathrm{~m}$

\section{Analisis Kinerja Tujuh Tahun Mendatang}

Tabel 6..Pertumbuhan Kendaraan

\begin{tabular}{|c|c|c|c|c|c|c|c|c|}
\hline \multirow{2}{*}{ No } & \multirow{2}{*}{ Tahun } & \multicolumn{4}{|c|}{ Jumlah Kendaraan } & \multicolumn{3}{|c|}{ Tingkat Pertumbuhan \% } \\
\hline & & $\mathrm{LV}$ & $\mathrm{HV}$ & $\mathrm{MC}$ & Total & LV & $\mathrm{HV}$ & $\mathrm{MC}$ \\
\hline 1 & 2016 & 5432 & 37 & 122874 & 128343 & $12 \%$ & $5 \%$ & $7 \%$ \\
\hline 2 & 2017 & 6116 & 39 & 132099 & 138254 & $11 \%$ & $5 \%$ & $8 \%$ \\
\hline 3 & 2018 & 6813 & 41 & 143082 & 149936 & $11 \%$ & $5 \%$ & $8 \%$ \\
\hline 4 & 2019 & 82974 & 726 & 715181 & 798881 & & & \\
\hline \multicolumn{6}{|c|}{ Rata - Rata } & $11 \%$ & $5 \%$ & $8 \%$ \\
\hline
\end{tabular}

Sumber. BPS Kota Jambi

Seperti yang dapat dilihat dari tabel di atas, dapat diketahui persentase pertumbuhan kendaraan tahunan dan laju pertumbuhan rata-rata Berdasarkan laju pertumbuhan jumlah kendaraan bermotor di wilayah tersebut, dapat diperoleh prakiraan arus lalu lintas untuk tahun 2027. Wilayah Kota Jambi. Nilai rata-rata variabel tahun dasar menggunakan data survei jumlah kendaraan yang melewati ruas jalan Kolonel Polsek Taher pada jam-jam sibuk tahun 2020. Untuk digunakan dalam analisis saturasi (DJ), jumlah kendaraan harus dikonversi. Kendaraan dalam satu unit mobil penumpang (smp). Untuk bisa mengganti satuan mobil penumpang (smp) digunakan nilai ekivalen kendaraan ringan (ekr) sesuai dengan jenis kendaraannya.

Tabel 7. Prediksi Arus Lalu Lintas Pada Jam Puncak Tahun 2027

Sumber. Hasil Perhitungan 2020

\begin{tabular}{cccc}
\hline LV & HV & MC & Jumlah \\
\hline 2047 & 50 & 850 & 2593 \\
\hline
\end{tabular}

Tabel 8. Nilai Arus Total (Q) Untuk Ruas Jln Kolonel Polisi Taher Tahun 2027

\begin{tabular}{cc}
\hline Tahun & Total Dua Lajur Dua Arah \\
\hline 2027 & 2593 \\
\hline
\end{tabular}

Sumber. Hasil Perhitungan 2020

Nilai arus total digunakan untuk menentukan derajat kejenuhan tahun 2027 dengan menggunakan hasil prediksi arus. total pada tahun 2027. Nilai kapasitas pada tahun 2027 di asumsikan meningkat di karenakan tidak ada perubahan pada ruas jalan yang ditinjau.

Berdasarkan analisis ruas jalan Kolonel Polisi M Taher pada tahun 2027 didapatkan nilai kapasitas ruas jalan yaitu $1473 \mathrm{smp} / \mathrm{jam}$ dan nilai derajat kejenuhannya yaitu 1,76 sehingga harus dilakukan penambahan kapasitas pada ruas jalan Kolonel Polisi M Taher. Dari hasil perhitungan dan analisa data, dapat diketahui tingkat pelayanan dan kepadatan jumlah kendaraan saat ini, dengan kapasitas ruas jalan yang masih dapat mencukupi pada jalan Kolonel Polisi M Taher.

\section{SIMPULAN}

Berdasarkan pengamatan dan analisis pada ruas jalan Kolonel polisi M Taher pada saat ini di peroleh kesimpulan sebagai berikut :

1. Nilai arus lalu lintas (Q) tertinggi terdapat di lengan Jln. Kol.Pol.M Taher arah Gr.Djamin Datuk Bagindo sebesar 1207 smp/jam. Nilai waktu siklus sebesar 104 detik dan waktu siklus yang disesuaikan adalah 100 detik. Nilai 
kapasitas untuk Jln.Kol.Pol M Taher dari arah Jln.Soekarno Hatta 1263 smp/jam, Jln. H.M yusuf Nasri 274 smp/jam, Jln.Kol.Pol.M Taher dari arah Gr.Djamin Datuk Bagindo 1473 smp/jam, dan Jln.Tengku Sulaiman 257 smp/jam.

2. Nilai derajat kejenuhan untuk Jln. Kol.Pol M Taher dari arah Jln.Soekarno Hatta DS 0,86 dengan tingkat pelayanan D sebagai arus tidak stabil, kecepatan rendah dan berbeda - beda, volume mendekati kapasitas. Jln. H M Yusuf Nasri DS 0,82. Dengan tingkat pelayanan jalan D, Jln. Kol.Pol M Taher arah Jln.Gr.Djamin Datuk Bagindo DS 0,86 dengan tingkat pelayanan D, Jln. Tengku Sulaiman DS0,82 dengan tingkat pelayanan D.

3. Melakukan pengkajian ulang mengenai fungsi kinerja rambu - rambu pengatur lalu lintas yang mana pada tahun 2020 DS 0,85 tahun 2027 DS 1,76 dalam hal ini perlunya di lakukan perbaikan pelebaran, dan pengaturan APILL guna mengatasi arus jenuh yang dapat meningkat melebihi kapasitas yang telah di tentukan pada tahun 2027.

4. Setelah dilakukan perhitungan prediksi arus lalu lintas yang akan terjadi pada tujuh tahun kedepan untuk ruas jalan Kolonel Polisi M Taher didapat bahwa nilai volume yang diperoleh pada tahun ketuju mencapai $2593 \mathrm{smp} / \mathrm{jam}$. Sehingga berdasarkan analisis ruas jalan Kolonel Polisi M Tahaer apabila tidak terjadi penambahan kapasitas ruas jalan yang nilai kapasitasnya yaitu $1473 \mathrm{smp} / j a m$ maka nilai derajat kejenuhannya akan mencapai nilai derajat.

\section{DAFTAR PUSTAKA}

Dani Prayoga Muhamad, Ircham, Diana Anis Anggorowati Veronica. 2020. Analisis Daya Tampung Jalan Dan Manajemen Lalu Lintas. Yogyakarta: Universitas Institut Teknologi Nasional.

Dwijoko, J. S. Dan, Anton Sujarwo. 2009. Evaluasi Dan Penanganan Simpang Empat Takbersinyal Menggunakan MKJI. Surabaya: Universitas Kristen Petra.

Direktorat Jendral Binamarga. 1997. Manual kapasitas jalan Indonesia (MKJI). Jakarta:Departemen Pekerjaan Umum RI.

Munawar. 1998. Manajemen lalu lintas. Yogyakarta: Universitas Gajah Mada.

Syahabudin, Febrina, Ishak. 2015. Perncanaan Lampu Pengatur Lalu Lintas Menggunakan Metode MKJI. Manado: Universitas Sam Ratulangi. 